\title{
Elastic-plastic time-history analysis of bridge seismic based on Opensees and IDA
}

\author{
Xianyan Luo ${ }^{1, a^{*}}$ \\ ${ }^{1}$ Department of civil engineering, Guangxi Polytechnic of Construction, Nanning 530004, China \\ alosebird1982@163.com
}

Keywords: Elastic-plastic, Bridge, Time-history analysis, OpenSees

\begin{abstract}
This paper uses the method of incremental dynamic analysis (IDA), by reading the control section concrete piers and steel strain calculation termination conditions, according to the existing specification design of high speed railway bridge, with the Beijing-shanghai high-speed railway and a large span $40 \mathrm{~m}+64 \mathrm{~m}+40 \mathrm{~m}$ continuous girder bridge as the research object, under severe earthquake, and on the elastic-plastic seismic response of nonlinear computation. The example analysis results can provide reference for seismic design of similar Bridges.
\end{abstract}

\section{Introduction}

The design method based on incremental dynamic analysis (IDA) is mainly embodied in the multi-level seismic codes. In this paper, the ductility seismic capacity of a long-span $40 \mathrm{~m}+64 \mathrm{~m}+$ $40 \mathrm{~m}$ continuous beam bridge in Beijing-Shanghai high-speed railway is calculated, the ductility seismic calculation under rare earthquake, and the nonlinear calculation of elastic-plastic seismic response under rare earthquake. Through the example, some useful conclusions are obtained.

\section{The Establishment of Finite Element Model}

The main beam of continuous beam adopts the c50 concrete Change beam, the pier adopts c50 concrete, the round end, the pier height from left to right ( 1 \# to 4 \#) are $21 \mathrm{~m}, 21 \mathrm{~m}, 20 \mathrm{~m}$ and 11.5 $\mathrm{m}$, respectively. The longitudinal reinforcement ratio and reinforcement ratio are shown in Table 1 .

The foundations are the pile foundations, Supports are the LXQZ-JH-III steel ball bearings. Establish the $40 m+64 m+40 m$ continuous girder bridge in OpenSees. As is shown in Fig. 1 .

Table 1. Each section and reinforcement of bridge pier bottom.

\begin{tabular}{c|c|c|c}
\hline Bridge pier & $1 \#, 4 \#$ & $2 \#$ & $3 \#$ \\
\hline Area $\left(\mathrm{m}^{2}\right)$ & 24.82 & 32.35 & 32.35 \\
\hline$\rho_{l}(\%)$ & $0.483(\phi 25)$ & $0.548(\phi 28)$ & $0.489(\phi 25)$ \\
\hline$\rho_{\omega}(\%)$ & $0.553(\phi 12)$ & $0.491(\phi 12)$ & $0.491(\phi 12)$ \\
\hline
\end{tabular}

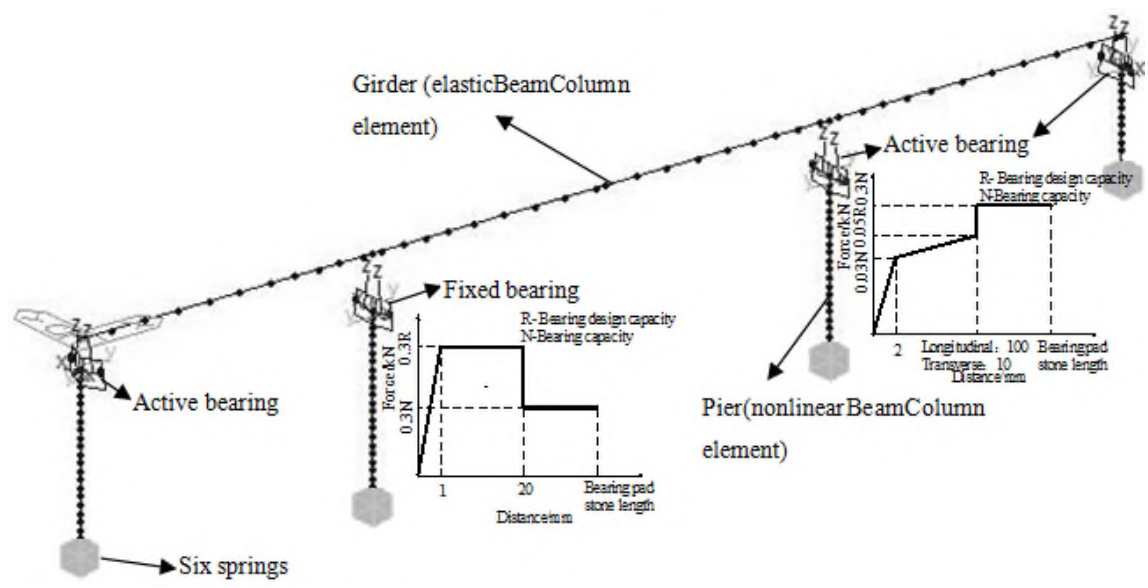

Fig. 1 Model of continuous beam bridge. 
The main beam is used to simulate the elastic beam column [1]. For the support system in the full bridge model, the support restoring force is simulated by the model shown in Fig. 1, and given Uniaxial Material hysteretic characteristics, to zero-length simulate in OpenSees, and given Uniaxial Material hysteretic characteristics; to zero-Length simulate. For the interaction between pile and soil, is simulated by zero-length-element in OpenSees. For the pier is simulated by non-linear Beam Column in OpenSees.

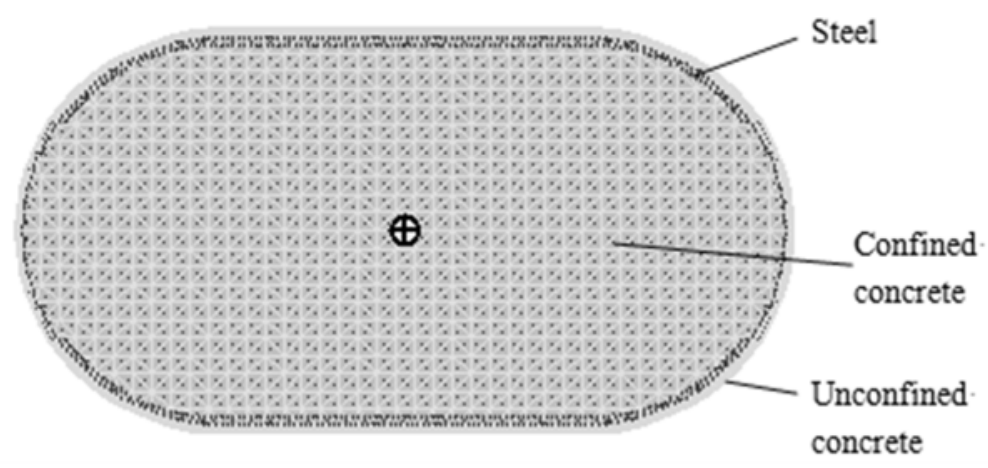

Fig. 2 Plastic hinge fiber model.

For the reinforced concrete pier of plastic hinge under simulated stress in different regions of the material classification performance, generally divided into unconstrained concrete, confined concrete and steel constitutive model can give different materials, as shown in Fig. 2.

For the fiber model of reinforced concrete bridge pier [2], it is necessary to select the corresponding material properties for each fiber according to the actual situation: the Mander model is selected for the confined concrete.

Uniaxial Material Concrete01 can be used to simulate the constitutive relationship of confined concrete and protective layer concrete in Opensees.

The Menegotto-Pinto model is used in the longitudinal reinforcement structure, as shown in Fig. 3. Opensees can be used to simulate the uniaxial Material Steel02 Menegotto-Pinto model of steel reinforcement.

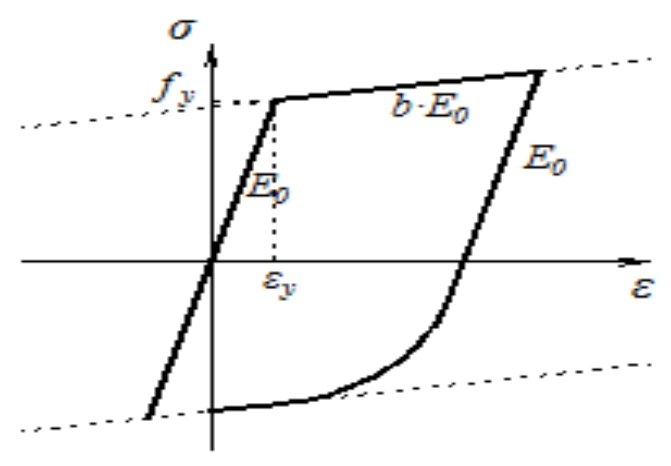

Fig. 3 Menegotto-Pinto model.

\section{Seismic Wave Selection}

The bridge is 8 degrees $0.2 \mathrm{~g}$ fortification, III site, the characteristic period divided into two regions. Selected 15 seismic records in accordance with the conditions from the Pacific earthquake engineering research center PEER earthquake database, and adjust the 15 seismic peak acceleration curve of the selected PGA, the interception near the peak area.

To adoption of seismic record and the railway engineering seismic code GB 50111-50111 (2009), comparing the design response spectrum with damping ratio for $5 \%$ of the dynamic amplification coefficient spectrum $\beta$ spectrum. Calculate each of the original record $\beta$ spectrum, get the average spectrum is shown in Fig. 4. 


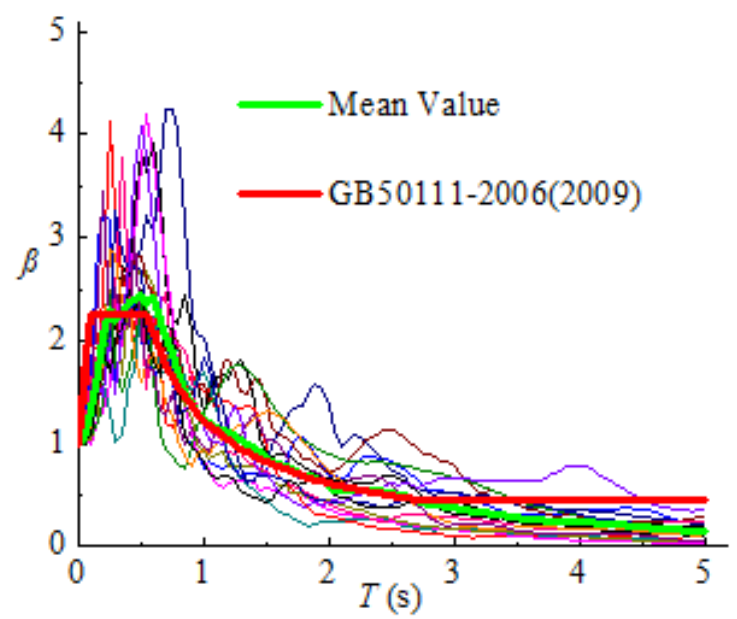

Fig. 4 The dynamic magnification coefficient spectrum.

\section{Time History Analysis}

According to the Fig. 5, the degree of dispersion of the tensile strain IDA curve of the steel bar is small before the yield of the longitudinal reinforcement, when the reinforcement reaches the yield strength, the curve turning point is more obvious, and then the dispersion degree of the curve becomes larger; When the tensile strain at the bottom section of the continuous girder bridge reaches 0.01 , the compressive strain of the core concrete can only reach 0.0016 0.0019; In a state of serious damage limit, continuous girder bridge pier bottom reinforcement tensile strain reaches 0.05 , the compressive strain of concrete can reach to $0.005 \sim 0.006$, far less than the Mander model to calculate the ultimate compressive strain of concrete core 0.01377 .
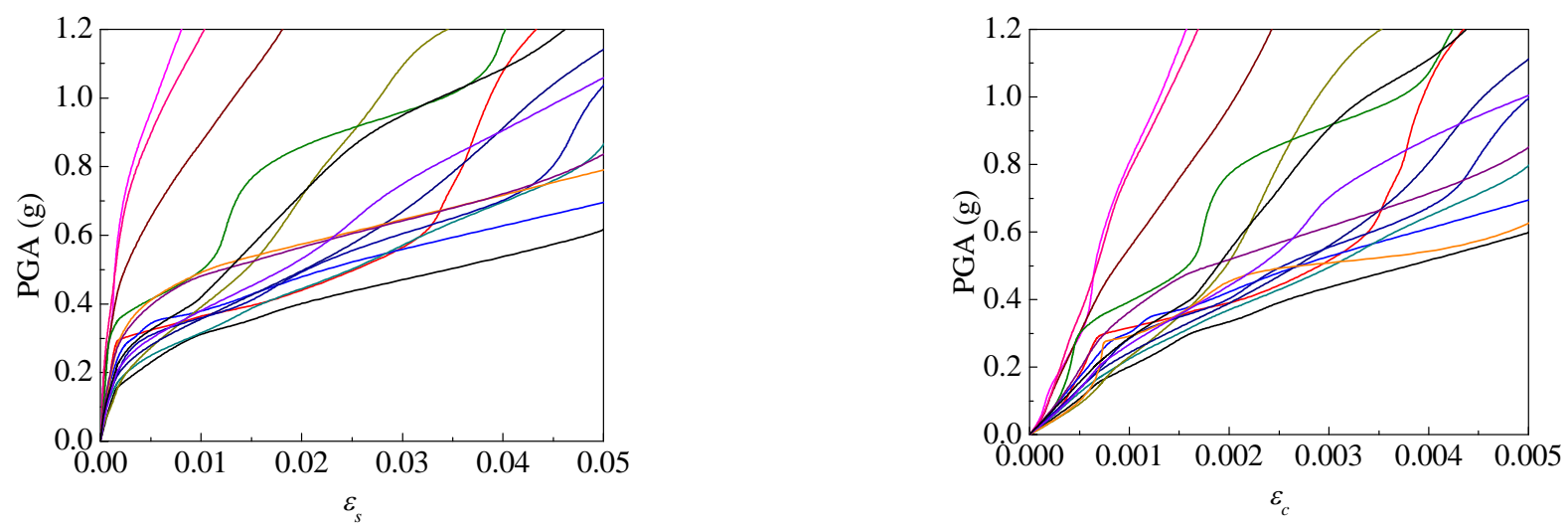

Fig. 5 Reinforcement strain and concrete compression strain curve of IDA.
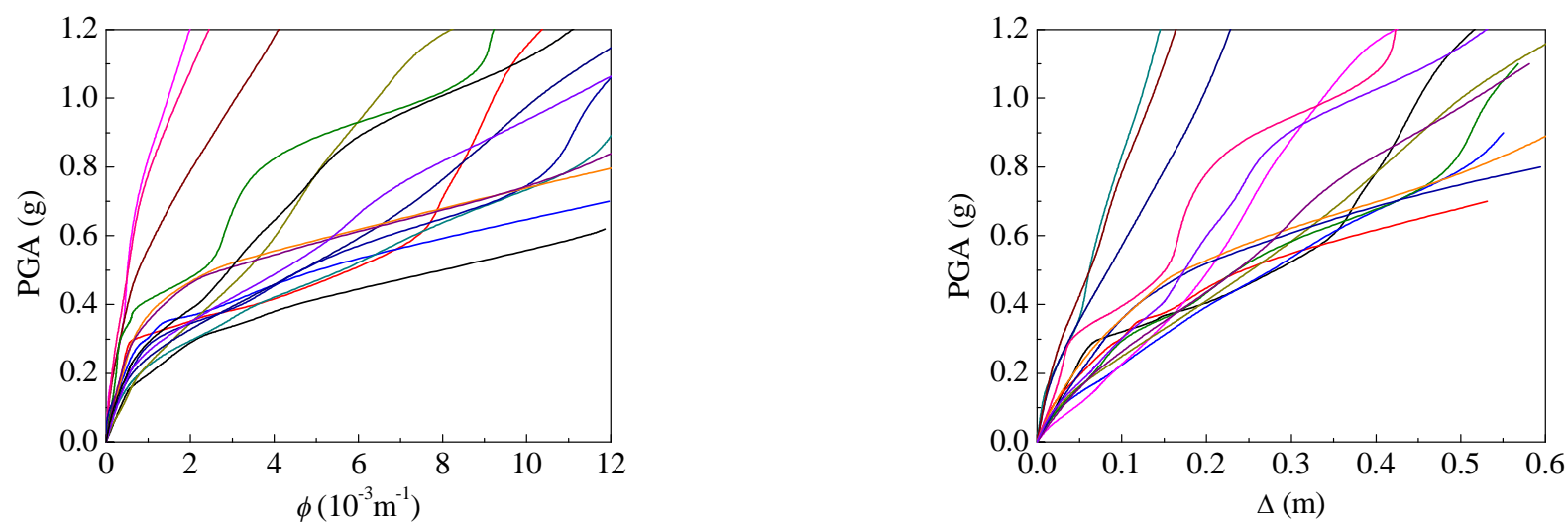

Fig. 6 Pier bottom section curvature $\phi$ and Pier top displacement $\Delta$ curve of IDA. 
It can be seen from the Fig. 6 that when the pier is in the elastic stage, the dispersion of the curve is not very large; when the pier plastic hinge until completely destroyed (collapse), the discrete curve will aggravate the larger, showing different characteristics of the buckling of the same strength, PGA, corresponding to a plurality of curvature and the reflecting spectrum of seismic wave on the structure of nonlinear response effect. Compared with the curvature curve, the displacement curve of pier top is nonlinear, so it can be considered that the rotation of plastic hinge area is not very obvious. Compared with the curvature curve, the displacement curve of pier top is nonlinear, so it can be considered that the rotation of plastic hinge area is not very obvious.

Also found that for such a large pier section of high-speed railway bridge, both the curvature IDA curve or IDA curve of displacement no turning point like frame column or small pier is very obvious, can only be determined by the control section of the concrete and reinforcement strain.

The secondary damage limit state, continuous girder bridge displacement ductility coefficient is 2.33 , the displacement ductility coefficient of serious damage limit state is 8.05 , can see the seismic capacity of bridge ductile than provisions of existing railway bridge seismic code allows the displacement ductility coefficient of 4.8. The IDA curve of the bottom section curvature of the bridge and the IDA curve of pier top displacement are fitted by the method [3, 4].

$$
\frac{\mathrm{EDP}}{\mathrm{EDP}_{c}}=\frac{\mathrm{EDP}}{K \cdot \mathrm{EDP}_{c}}\left(1+b\left|\frac{\mathrm{IM}}{\mathrm{IM}_{c}}\right|^{r-1}\right)
$$

Table 2. Fitting results of control parameters and standard deviation of IDA.

\begin{tabular}{c|c|c|c|c|c|c}
\hline & \multicolumn{3}{|c|}{ Curvature IDA curve } & \multicolumn{3}{c}{ Displacement IDA curve } \\
\hline Parameter & IMc & $\mathrm{K}$ & $\mathrm{r}$ & $\mathrm{IMc}$ & $\mathrm{K}$ & $\mathrm{r}$ \\
\hline $50 \%$ digit & 1.41 & 470.71 & 2.4 & 1.41 & 3.82 & 3 \\
\hline$\beta$ & 0.57 & 0.43 & - & 0.57 & 0.49 & - \\
\hline
\end{tabular}
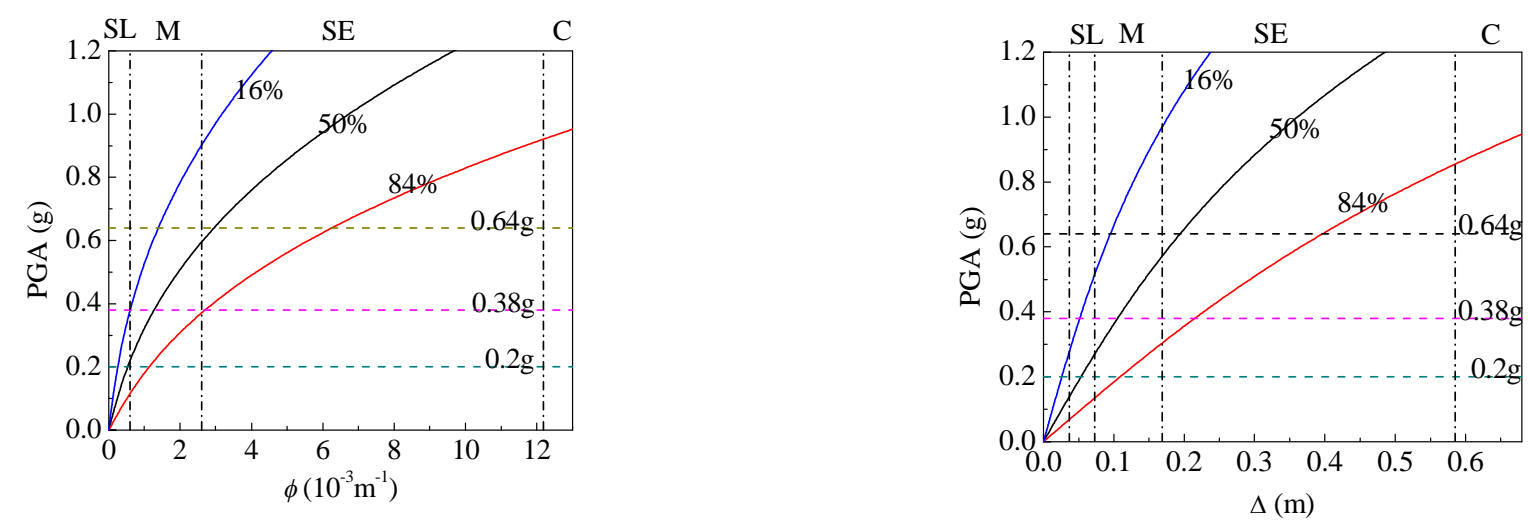

Fig. 7 The pier bottom section curvature and IDA quantile pier top displacement curve.

Learned from Fig. 7, the local vibration intensity were $0.2 \mathrm{~g}$ (design earthquake) and $0.38 \mathrm{~g}$ (rare earthquake) and $0.64 \mathrm{~g}$ (extremely rare earthquake), the pier top displacement are respectively $0.0532 \mathrm{~m}, 0.1049 \mathrm{~m}$ and $0.1934 \mathrm{~m}$, the displacement ductility ratio of 0.73 and 1.44 (elastic state) and 2.66, respectively in the minor damage state, the secondary damage and serious damage, not collapse phenomenon.

\section{Conclusion}

According to the dynamic analysis (IDA) method, through Opensees software on the time history analysis of high-speed continuous girder bridge, according to the seismic performance is good, the result shows that the beam bridge meet the ductility calculation under severe earthquake action. Therefore, according to the current seismic code for bridge design meet the engineering is can meet the engineering need. 


\section{References}

[1] K. J. Bathe, Large displacement analysis of three dimensional beam structures. Int. J. Numer. Meth. Eng. 4 (1979) 961-986.

[2] M. J. Kowalsky, A displacement-based approach for the seismic design of continuous concrete bridges, Earthq. Eng. Struct. Dyn. 31 (2002) 719-747.

[3] AISC Seismic Provisions for Steel Buildings, American Institute of Steel Construction, Inc, Chicago. Wai-Fah Chen, Bridge Engineering Handbook, CRC Press, (2000), pp. 12-19.

[4] R. W. Clough, Dynamics of structures, Computers \& Structures, Inc. (1995), pp. 10-13. 